\section{Pacific Northwest}

National Laboratory

Operated by Battelle for the

U.S. Department of Energy

\title{
Energy End-Use Flow Maps for the Buildings Sector
}

D.B. Belzer

September 2006

Prepared for the U.S. Department of Energy under Contract DE-AC06-76RL01830 


\title{
DISCLAIMER
}

This report was prepared as an account of work sponsored by an agency of the United States Government. Neither the United States Government nor any agency thereof, nor Battelle Memorial Institute, nor any of their employees, makes any warranty, express or implied, or assumes any legal liability or responsibility for the accuracy, completeness, or usefulness of any information, apparatus, product, or process disclosed, or represents that its use would not infringe privately owned rights. Reference herein to any specific commercial product, process, or service by trade name, trademark, manufacturer, or otherwise does not necessarily constitute or imply its endorsement, recommendation, or favoring by the United States Government or any agency thereof, or Battelle Memorial Institute. The views and opinions of authors expressed herein do not necessarily state or reflect those of the United States Government or any agency thereof.

\author{
PACIFIC NORTHWEST NATIONAL LABORATORY \\ operated by \\ BATTELLE \\ for the \\ UNITED STATES DEPARTMENT OF ENERGY \\ under Contract DE-AC06-76RL01830
}

Printed in the United States of America
Available to DOE and DOE contractors from the Office of Scientific and Technical Information, P.O. Box 62, Oak Ridge, TN 37831-0062; ph: (865) 576-8401 fax: (865) 576-5728
email: reports@adonis.osti.gov

\begin{abstract}
Available to the public from the National Technical Information Service, U.S. Department of Commerce, 5285 Port Royal Rd., Springfield, VA 22161 ph: (800) 553-6847 fax: (703) 605-6900 email: orders@ntis.fedworld.gov online ordering: http://www.ntis.gov/ordering.htm
\end{abstract}


PNNL-16263

\section{Energy End-Use Flow Maps for the Buildings Sector}

D.B. Belzer

September 2006

Prepared for

the U.S. Department of Energy

under Contract DE-AC06-76RL01830

Pacific Northwest National Laboratory

Richland, Washington 99352 



\section{Summary}

Graphical presentations of energy flows are widely used within the industrial sector to depict energy production and use. PNNL developed two energy flow maps, one each for the residential and commercial buildings sectors, in response to a need for a clear, concise, graphical depiction of the flows of energy from source to end-use in the building sector.

The body of the report contains the Residential and Commercial sector Energy Flow Maps. An appendix containing source notes on the data behind the flow maps follows. 


\section{Contents}

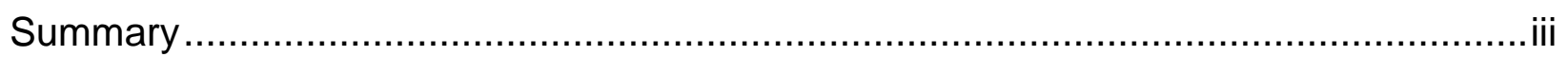

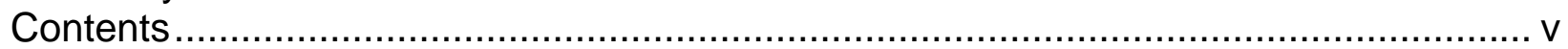

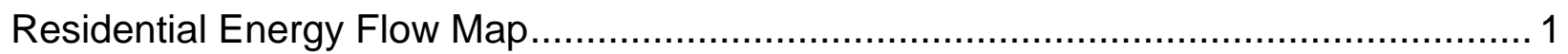

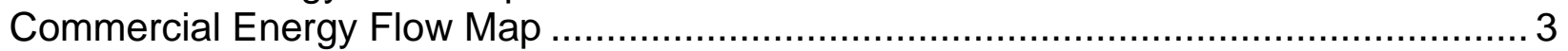

Appendix: Source Notes for Building Sector Energy Flow Maps .............................A-1

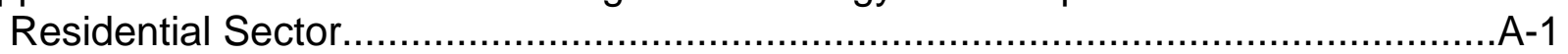

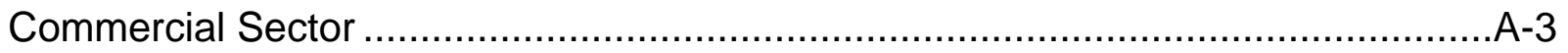




\section{Residential Energy Flow Map}

The following figure illustrates the residential sector flow of energy from source to end use. 


\section{Energy Flow Chart - 2004 Residential Sector}

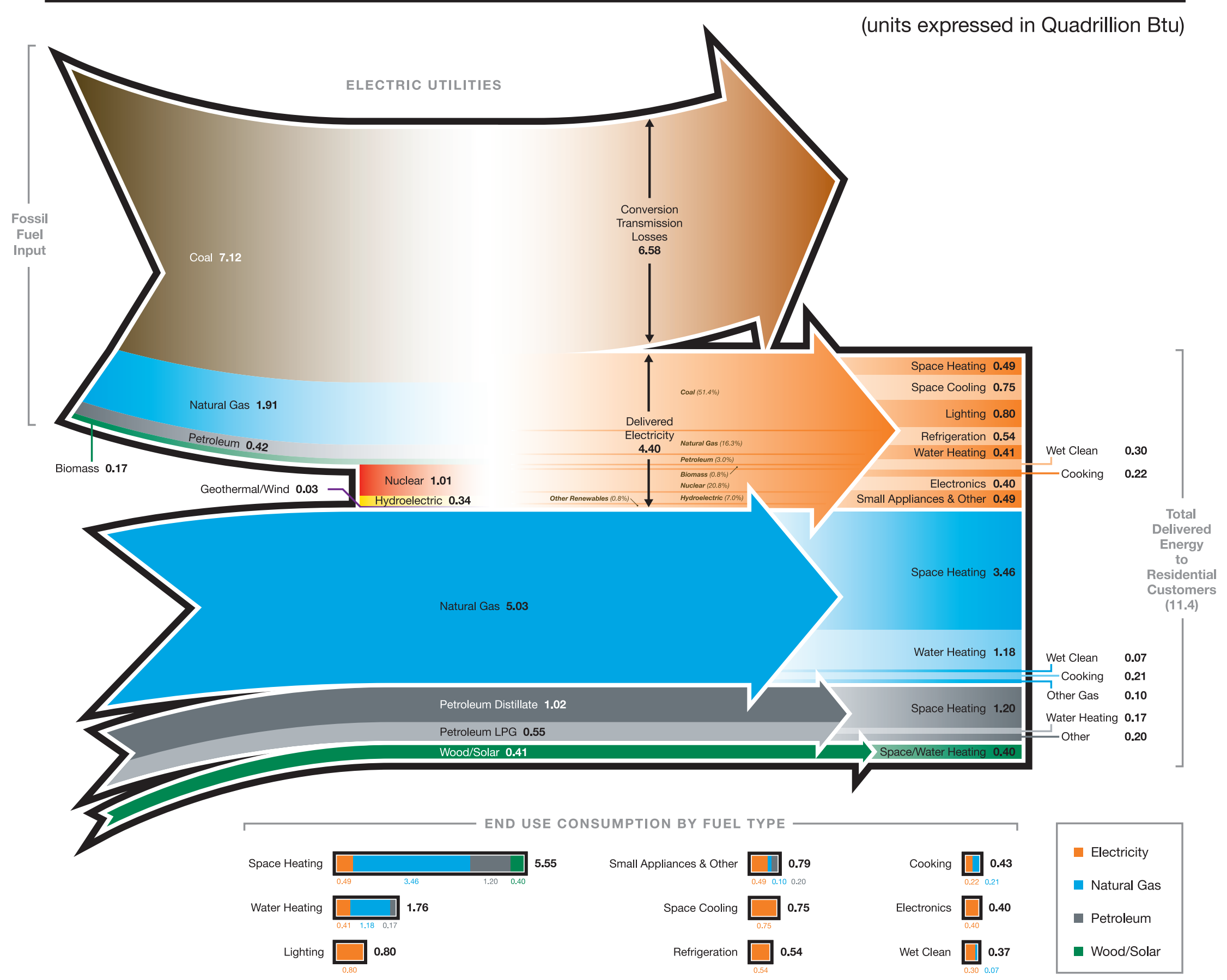




\section{Commercial Energy Flow Map}

The following figure illustrates the commercial sector flow of energy from source to end use. 


\section{Energy Flow Chart - 2004 Commercial Sector}

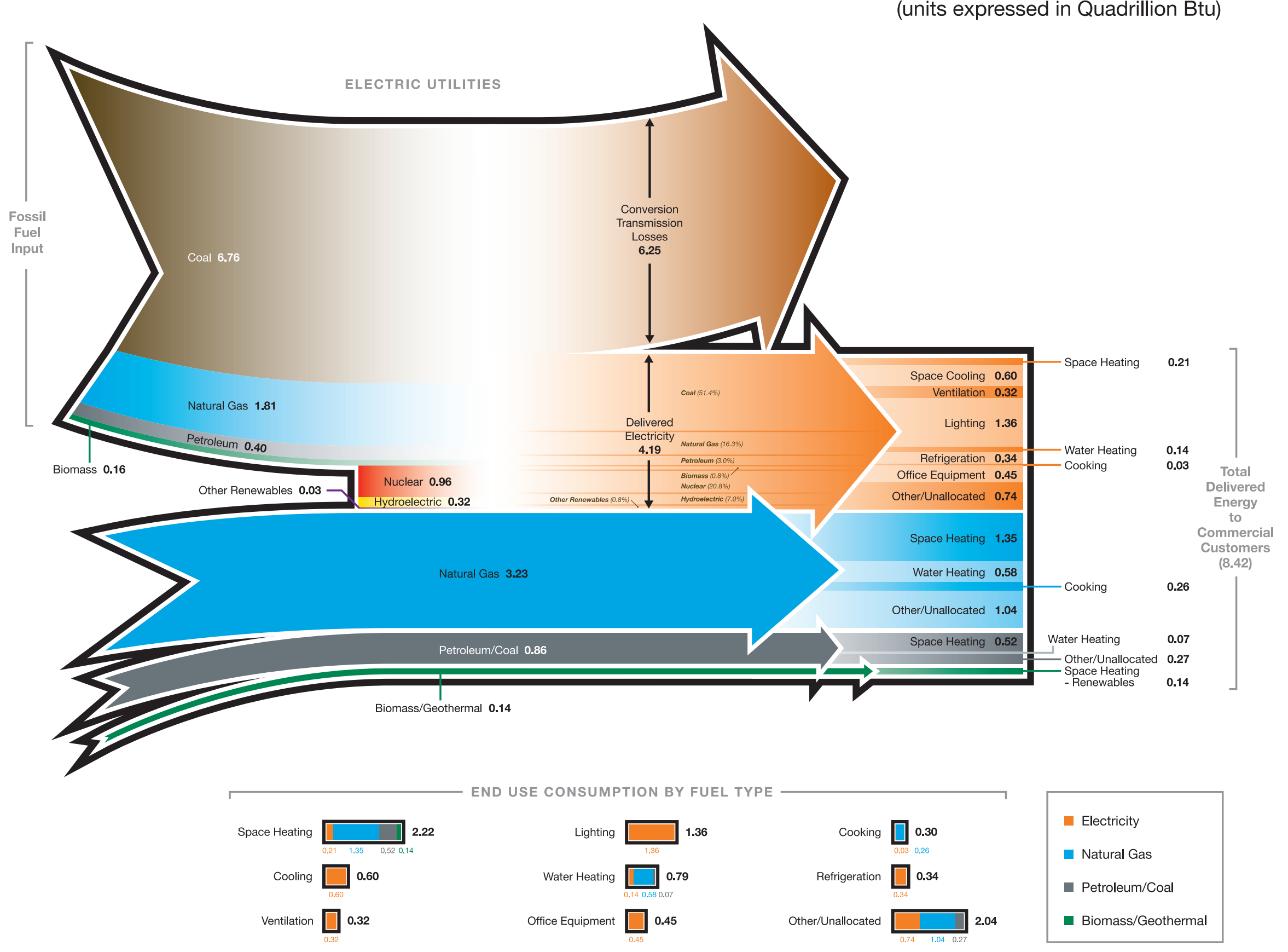




\section{Appendix: Source Notes for Building Sector Energy Flow Maps}

\section{Residential Sector}

\section{Source Energy (left side of map)}

Electricity. The process of developing source energy related to residential electricity use begins by developing a distribution of electricity generation by fuel and technology (plant type). The distribution of electricity generation by plant type is derived from Table 8.3c from the 2004 Annual Energy Review [EIA-0384(2004)] and is based upon both electricity-only and combined heat and power plants. This distribution is then applied to the total retail sales of electricity to the residential sector from Table 2.1b of the 2004 Annual Energy Review (AER). In developing the distribution from Table 8.3c, the entries for hydroelectric pumping plants and "Other" were ignored (pumping plants are net users of electricity [about $0.2 \%$ of total generation] and "Other" constitutes less the $0.1 \%$ of total generation.) (Ideally, a residential sector-specific distribution of electricity generation by plant type would be desirable, as the hourly demand profile of residential customers is not the same as for all users of electricity. A differential demand profile would imply different generation mixes to meet peak load demands. However, readily accessible data was not available to construct such a distribution.)

The fuel inputs required by the electric power sector to generate the quantity of electricity used by the residential sector are based on estimates made for DOE/EERE's Energy Intensity Indicators project. These estimates are derived from Tables 8.4b and 8.5c in the 2004 AER. In essence, a typical "heat rate" is estimated for each type of plant-i.e., the number of Btu required to generate one $\mathrm{kWh}$ of electricity. The derivation of the heat rate estimates is incorporated in the Electricity_indicators.xls spreadsheet that can be downloaded from the EERE web site (http://www1.eere.energy.gov/ba/pba/market_data.html.). The specific worksheets with the fossil energy generation plants are: "Electricity_only $>$ fossil" and "Elec_power_sector_CHP>fossil.” For renewable energy, the worksheets are: "Electricity_only>renewable” and “Elec_power_sector_CHP>renewable.” The heat rate for each type of plant (e.g., natural gas fired plants) is an average of electricity-only and CHP plants.

As a departure from the EIA accounting convention, the flow map does not impute any generation losses to nuclear, hydroelectric, or renewable technologies. This treatment provides a more accurate representation of the carbon impacts from residential energy use.

The final step is to add transmission and distribution (T\&D) losses for electricity. Based upon Diagram 5 in the Electricity chapter in the 2004 AER, T\&D losses were estimated by EIA to be about $10.1 \%$ of total end-use deliveries of electricity. This percentage was applied uniformly to the electricity retail sales by plant type derived above.

Total source energy by plant (fuel) type applicable to residential electricity use is then imputed as the sum of the total fuel for generation plus estimated transmission losses. This sum is equal 
to Delivered Electricity and Conversion/Transmission Losses as shown in the top portion of the flow map.

Other Fuels. The direct consumption of energy other than electricity is taken from Table 2.1b of the 2004 AER. The breakout of petroleum into distillate and LPG is based upon data published in the 2005 Buildings Energy Databook published by EERE/BT (web address: http://buildingsdatabook.eren.doe.gov/ - see further discussion below.) The entry for "wood" at the very bottom of the map includes solar ( 15\% of the total) and geothermal ( 5\% of the total.)

(Following EIA convention, no separate estimates for transmission and distribution losses are made for fuels other than electricity. For natural gas, EIA assigns natural gas energy used for the operation of gas pipelines [primarily used in compressors] to transportation sector use. This pipeline consumption is about $2.6 \%$ of retail gas deliveries. If this consumption were added to the residential sales to represent losses similar to the $T \& D$ losses for electricity, the source natural gas use would increase by about 0.13 Quadrillion Btu [QBtu]. To simplify the flow maps, this small flow has not been shown.)

\section{End-Use Distribution (right side of map and horizontal bar charts)}

The distribution of energy by end use is based upon estimates developed for the 2005 Buildings Energy Databook (BED). The 2005 BED contains estimates of end use and fuel for residential sector energy use for 2003 (Table 1.2.3).

The following notes are applicable to the breakout of end uses derived from the BED. Space heating includes electricity used for furnace fans (approximately $50 \%$ of the total electricity shown for space heating). Refrigeration includes both refrigerators and freezers. Wet clean includes both clothes washers and dryers as well as dishwashers.

Electronics includes television and other home entertainment equipment. Computers, which are broken out separately in the BED, are included in electronics for the flow map. Small Appliances and Other shown in the flow map is the sum of "Other" and "Adjust to SEDS" in the BED. The “Adjust to SEDS” is EIA's adjustment to reconcile supply-side (State Energy Data System, [SEDS]), and end-user (principally, the Residential Energy Consumption Survey) estimates of energy use. The 2005 BED indicated that about 60\% of the energy in this combined Small Appliances and Other category can be attributed to this adjustment.

As the BED estimates are published for 2003, some scaling was performed to match the 2004 energy use totals by fuel type. Because total electricity from the BED for 2003 was within about one percent of total electricity consumption for 2004 (from the AER), all end uses from the BED were scaled proportionately to match the 2004. Natural gas consumption for 2004 from the AER was about 4\% higher than the 2003 total in the BED. The BED estimates for end uses other than space heating were scaled up by $1 \%$ (to roughly match population growth), and the remaining discrepancy was allocated to space heating. For petroleum, the difference between the 2003 BED estimates and 2004 value from the AER was just over one percent. A small downward adjustment to the distillate used for space heating was made to match the total petroleum use for 2004. The BED provided separate end-use distributions for distillate and LPG. 
In the flow map, these estimates are combined (yielding a distribution of end use consumption for petroleum products into space heating, water heating, and other.) As mentioned previously, the flow labeled "wood" at the bottom of the map contains some solar and geothermal energy. While the end use associated with this energy is denoted as space heating, a small portion of this energy flow is used for water heating (estimated to be between $5 \%$ and $15 \%$ of the total.)

\section{Commercial Sector}

\section{Source Energy (left side of map)}

Electricity. The process of developing source energy for commercial electricity use begins by developing a distribution of electricity generation by fuel and technology. The distribution of electricity generation by plant type is derived from Table 8.3c from the 2004 Annual Energy Review [EIA-0384(2005)] and is based upon both electricity-only and combined heat and power plants. This distribution is then applied to the total 2004 retail sales of electricity to the commercial sector from Table 2.1c of the 2005 Annual Energy Review (AER). In developing the distribution from Table 8.3c, the entries for hydroelectric pumping plants and "Other" were ignored (pumping plants are net users of electricity [about $0.2 \%$ of total generation] and "Other" constitutes less the $0.1 \%$ of total generation.) (Ideally, a commercial sector-specific distribution of electricity generation by plant type would be desirable, as the hourly demand profile of commercial customers is not the same as for all users of electricity. However, readily accessible data was not available to make such a distribution.)

The fuel inputs required by the electric power sector to generate the quantity of electricity used by the commercial sector are based on estimates made for DOE/EERE's energy intensity indicators project. These estimates are derived from Tables 8.4b and 8.5c in the 2004 AER. In essence, a typical "heat rate" is estimated for each type of plant-i.e., the number of Btu required to generate one kWh of electricity. The derivation of the estimates is incorporated in the Electricity_indicators.xls spreadsheet that can be downloaded from the EERE web site (http://www1.eere.energy.gov/ba/pba/market_data.html.). The specific worksheets with the generation fossil energy are: "Electricity_only $>$ fossil” and "Elec_power_sector_CHP $>$ fossil." For renewable energy, the worksheets are: "Electricity_only>renewable" and "Elec_power_sector_CHP>renewable." The heat rate for each major type of plant (e.g., natural gas fired plants) is an average of electricity-only and CHP plants.

As a departure from the EIA accounting convention, the flow map does not impute any generation losses to nuclear, hydroelectric, or renewable technologies. This treatment provides a more accurate representation of the carbon impacts from commercial energy use.

The final step is to add transmission and distribution (T\&D) losses for electricity. Based upon Diagram 5 in the Electricity chapter in the 2004 AER, T\&D losses were about $10.1 \%$ of total end-use deliveries of electricity. This percentage was applied uniformly to the electricity retail sales by plant type derived above. 
Total source energy by plant type applicable to commercial electricity use is then imputed as the sum of generation energy use and transmission losses. This sum is equal to Delivered Electricity and Conversion/Transmission Losses as shown in the top portion of the flow map.

Other Fuels. The direct consumption of energy other than electricity is taken from Table 2.1c of the 2005 AER. The entry for "Biomass/geothermal" at the very bottom of the map breaks out into about $40 \%$ from wood, $46 \%$ from waste, and 14\% from geothermal energy.).

(Following EIA convention, no separate estimates for transmission and distribution losses are made for fuels other than electricity. For natural gas, EIA assigns natural gas energy used for the operation of gas pipelines (primarily used in compressors) to transportation sector use. This pipeline consumption is about $2.6 \%$ of retail gas deliveries. If this consumption were added to commercial gas sales to represent losses similar to the T\&D losses for electricity, the source natural gas use would increase by about 0.08 QBtu. To simplify the flow maps, this small flow has not been shown.)

\section{End-Use Distribution (right side of map and horizontal bar charts)}

The distribution of energy by end use is based upon estimates developed for the 2005 Buildings Energy Databook (BED). The 2005 BED contains estimates of end use and fuel for commercial sector energy use for 2003 (Table 1.3.3).

The following notes are applicable to the breakout of end uses derived from the BED. Electronics is assumed to consist primarily of office equipment other than computers. Computers, separately identified in the BED, are included in electronics for the flow map. In the flow map, "Other/Unallocated is the sum of "Other" and "Adjust to SEDS" in the BED. The “Adjust to SEDS” is EIA's adjustment to reconcile supply-side (State Energy Data System, [SEDS]), and end-use (principally, the Commercial Energy Consumption Survey) estimates of energy use. The 2005 BED indicated that 1.3 QBtu fell into this category. (In the BED, the most of the energy from LPG and renewable sources were assigned to the "Other" end use; in the flow map this consumption has been reassigned to space heating).

As the most recent BED estimates are available for 2003, some scaling was performed to match the 2004 energy use totals by fuel type (taken from the 2006 AER). Because total electricity from the BED for 2003 was within about 1.5 percent of total electricity consumption for 2004 (from the AER), all end uses from the BED were scaled proportionately to match the 2004 total. Natural gas consumption for 2004 from the AER was almost identical to the BED (3.23 QBtu in the AER vs. 3.22 in BED). The BED estimates for end uses other than space heating were scaled up by $1.4 \%$ (to roughly match an estimate of the growth in commercial floor space - taken from the commercial_indicators.xls spreadsheet on the Energy Intensity Indicators website), and the very small remaining discrepancy was allocated to space heating. For petroleum, the difference between the 2003 BED estimates and 2004 value from the AER was only about one-half of one percent. (The BED petroleum numbers include fuel oil, kerosene, and motor oil - see notes to BED Table 1.3.3). In the energy flow map, the consumption for coal (0.101 QBtu) is added to petroleum and is assumed to be entirely used for space heating. 